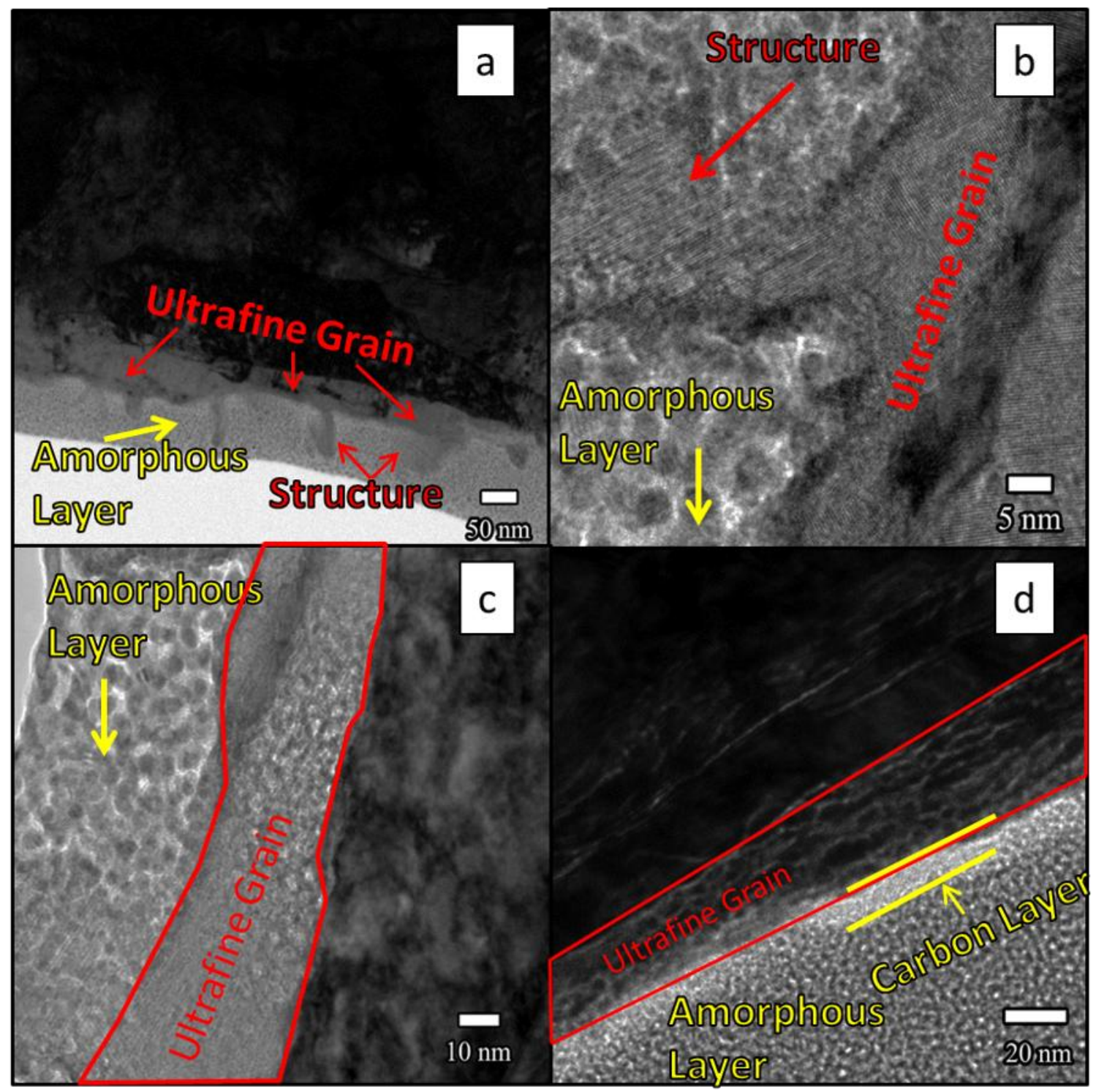

TEM micrographs of the ultrafine-grained tungsten sample irradiated with $30 \mathrm{eV}$ He particles to a fluence of $1 \times 10^{23} \mathrm{~m}^{-2}$ at $600{ }^{\circ} \mathrm{C}$ showing (a) several rod-shape nanostructures; (b) high resolution image of a rod-shape nanostructure; (c) region of bubbles in between two rod-shape nanostructures and (d) region of highly dense large bubbles $\sim 10 \mathrm{~nm}$ below the sample surface. Images in (c) and (d) were taken at under-focus conditions. 


\title{
Early stage damage of ultrafine-grained tungsten materials exposed to low energy helium ion irradiation
}

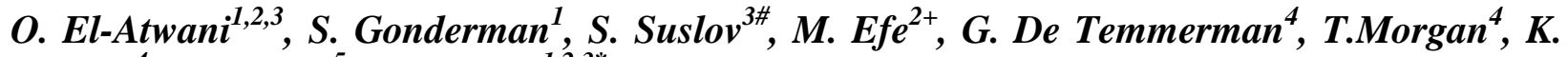

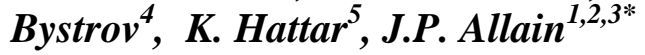 \\ ${ }^{1}$ School of Nuclear Engineering, Purdue University, West Lafayette, IN 47906 \\ ${ }^{2}$ School of Materials Engineering, Purdue University, West Lafayette, IN 47906 \\ ${ }^{3}$ Birck Nanotechnology Center, Purdue University, West Lafayette, IN 47906 \\ ${ }^{4}$ FOM Institute DIFFER-Dutch Institute for Fundamental Energy Research \\ (DIFFER),Edisonbaan 14,3439 MN, Nieuwegein, Netherlands \\ ${ }^{5}$ Department of Radiation Solid Interactions, Sandia National Laboratories, Albuquerque, NM \\ 87185
}

\begin{abstract}
Tungsten is considered as a plasma facing component in the divertor region of the International Thermonuclear Experiment Reactor (ITER). High flux, high fluence helium (He) exposure of tungsten surfaces induces severe morphology changes and nanostructure formation, which may eventually erode tungsten and risk the operation of the reactor. In this study, we investigate the response of ultrafine-grained tungsten under low flux $\left(\sim 10^{20}\right.$ ions $\left.\mathrm{m}^{-2} \mathrm{~s}^{-1}\right)$, low fluence, low energy (30-70 eV) He irradiation at different temperatures in order to study the early stage of nanostructure formation. Rod-shape nanostructures formed at low temperatures $\left(600{ }^{\circ} \mathrm{C}\right)$ and a He fluence of $1 \times 10^{23} \mathrm{~m}^{-2}$. High resolution, cross-section TEM images of irradiated grains demonstrated bubble formation not inside the nanostructures but deep inside the grains. At higher temperatures $\left(900{ }^{\circ} \mathrm{C}\right)$ and the same fluence of $1 \times 10^{23} \mathrm{~m}^{-2}$, large tungsten asperities (stone-shape and fiber-form structures), which are attributed to the burst and erosion of the surface grains. Moreover, low fluence $\left(10^{20} \mathrm{~m}^{-2}\right.$ to $\left.10^{21} \mathrm{~m}^{-2}\right)$ and high temperature $\left(900{ }^{\circ} \mathrm{C}\right)$ irradiation demonstrated low density of non-coalesced bubbles inside the TEM samples. The results suggest that morphology changes can exist in He irradiated tungsten even with low
\end{abstract}


bubble densities, thus, an additional factor such as surface stresses may dictate the observed nanostructure formation.

${ }^{\#}$ Current address: Qatar Environment and Energy Research Institute, Qatar Foundation, Doha, Qatar

+Current address: Department of Metallurgical and Materials Engineering, METU, Ankara, Turkey

*Current address: Department of Nuclear, Plasma and Radiological Engineering, University of Illinois at Urbana-Champaign, Urbana, IL 61801

\section{Introduction}

Currently, tungsten remains a prime candidate as a plasma facing component in current and future fusion reactor designs, due to its relatively low erosion rate and various thermal and mechanical properties [1, 2]. However, tungsten performing under fusion environments has shown potentially detrimental morphology changes on its plasma facing surfaces [3, 4]. In addition, He concentrations in bulk tungsten expected from neutron-driven transmutation at free surfaces (e.g. grain boundaries) also presents a challenge. Bubbles [5], pores [6], fuzz [7], and blistering [8] are among these changes when tungsten is exposed to high flux, high fluence ion irradiations. Helium bubble formation is suggested as the primary mechanism responsible from these damages [9, 10]. Then, tungsten materials trapping less helium intra-granularly should demonstrate more damage resistance. Accordingly, recent literature has shown that materials with higher grain boundary density may have greater radiation resistance. Bai et al. [11] indicated grain boundaries in nanocrystalline $\mathrm{Cu}$ as defect sinks. Grain boundaries absorb interstitials formed during the collision cascade caused by incident ions. Similarly, slower moving vacancies that approach grain boundaries combine with re-emitted interstitial atoms and thus annihilate [11]. Other studies demonstrated grain boundaries as defect sinks that reduce the 
amound of irradiation-induced defects in nanocrystalline $\mathrm{Ni}$ and $\mathrm{Cu}$ grains [12] and helium damage in $\mathrm{Cu}-\mathrm{Nb}$ multilayer nanocomposites [13]. These grain boundary effects prevent formation of large defects like bubbles or dislocation loops near the grain boundaries and creates a region known as the denuded zone (few tens of nm from grain boundaries) [14] where there is minimal concentration of bubbles or other structures associated with radiation damage. Nevertheless, the expected higher concentration of $\mathrm{He}$ defects at the grain boundaries exacerbated by large grain-boundary density (which can lead to mechanical degradation [15]) and the intrinsic thermodynamic instability of extreme-grain metals render their use in extreme plasma-burning fusion environments arguably limited.

The relationship between the helium bubbles and damage evolution on tungsten surfaces is explained by the following theory [10]. In the initial stage, helium bubbles are formed on or near the surface. With increasing exposure, larger bubbles begin to coalesce and blister on the surface. Irradiation-induced diffusion leads to dips, holes and other surface features and further irradiation of the bubbles causes them to burst and create protrusions in the form of fibrous nanostructures. These nanostructures eventually evolve into to the fuzz structure observed on tungsten at high fluences [16]. However, in previous work we demonstrated that similar damage can occur at low fluxes $\left(\sim 2-3 \times 10^{18} \mathrm{~cm}^{-2}\right)$, low fluences $\left(1 \times 10^{18} \mathrm{~cm}^{-2}\right)$, and low incident ion energy (200 eV - energy well below the physical sputtering threshold of tungsten) [17]. At these low fluxes and fluences, damage mechanism can differ from existing high flux theories. As an example, ultrafine grains were separated from large grained matrix because of enhanced surface diffusion and grain boundary grooving. Therefore, low-flux irradiation of ultrafine grain tungsten during the early stages of damage formation combined with cross-section TEM imaging can elucidate the damage evolution on tungsten surfaces and demonstrate any possible 
advantage/disadvantage of ultrafine-grained (UFG) tungsten over commercially available largegrained tungsten. In light of our previous findings, we now report on low flux and low fluence helium irradiation results of all ultrafine-grained samples prepared by a surface deformation technique. Effects of temperature, fluence and incident ion energy on early stage damage are also discussed.

\section{Experimental}

The UFG tungsten materials were prepared by extrusion machining [18], a severe plastic deformation (SPD) method capable of refining the microstructure of the chips and the workpiece surface. Sample preparation details were reported in the previous work [18].

All samples discussed were exposed in the Nano-PSI device which is similar to the PilotPSI [19] linear plasma device. Nano-PSI [20] is an expanding thermal plasma device. The plasma is generated by a cascaded arc discharge, which freely expands in the vacuum vessel. The result is a machine that can generate fluxes much higher than traditional ion sources $\left(\sim 10^{18}\right.$ ions $\mathrm{m}^{-2} \mathrm{~s}^{-1}$ ) but lower fluxes than the fluxes observed in typical linear plasma devices. This allows the investigation of early stage fuzz formation. The flux was almost constant ranging only $\sim 9 \mathrm{x}$ $10^{19}-2 \times 10^{20}$ ions $\mathrm{m}^{-2} \mathrm{~s}^{-1}$. The fluences was controlled over the range of $\sim 1 \times 10^{21}-1 \times 10^{24}$

ions $\mathrm{m}^{-2}$, the sample bias ranged from -30 and $-70 \mathrm{~V}$, and the sample temperatures was controlled from $300-900{ }^{\circ} \mathrm{C}$. The temperature of the sample was set using a heater. In contrast to the samples in Pilot-PSI that are heated by the plasma, no significant heating occurred by the incident ions from the plasma in the Nano-PSI. All irradiations were performed at normal incidence.

Post-irradiation characterization took place at Birck Nanotechnology Center at Purdue 
University. To study the damage that occurred as a result of the irradiation environment, scanning electron microscopy (SEM) and transmission electron microscopy (TEM) were performed using Hitachi S4800 FESEM and FEI Titan 80/300 field emission TEM (operating at $300 \mathrm{kV}$ ), respectively. Cross-section TEM samples from irradiated surfaces were prepared using FEI xT Nova NanoLab Dual Beam focused ion beam/scanning electron microscope (FIB/SEM). During the sample preparation step, the electron beam was first used to navigate to a fresh area of the sample. After that, $200 \mathrm{~nm}$ of Pt/C protective layer (usually a mixture of Pt and C) was deposited using e-beam deposition (energy of the e-beam was $10 \mathrm{keV}$ ), and the rest of the thickness $(\sim 1.3 \mu \mathrm{m})$ was deposited using Ga-beam deposition (energy of the beam was $30 \mathrm{keV}$ and the current was $0.3 \mathrm{nA}$ ). The width of the Pt slab was about $2 \mu \mathrm{m}$. Proper cleaning of the near surface region enabled the high resolution imaging. This is done by decreasing the ion beam $(30 \mathrm{keV})$ current as the cutting approaches the Pt protective layer with $30 \mathrm{pA}$ as the final milling current. After that, the Ga-beam energy was reduced in two steps to 10 and $5 \mathrm{keV}$ to reduce the thickness of the amorphous damaged layer on the sides of the sample.

TEM samples obtained by electropolishing were also irradiated using Nano-PSI as described above. In this case, a twin-jet electropolishing technique with $0.5 \% \mathrm{NaOH}$-water solution was employed to eliminate any possible irradiation damage from FIB or ion milling techniques.

\section{Results and Discussion}

Figure 1 shows the SEM images of UFG tungsten samples (with grain widths smaller than $500 \mathrm{~nm}$ ) irradiated with $30 \mathrm{eV}$ He ions to a fluence of $1 \times 10^{23} \mathrm{~m}^{-2}$ at different temperatures. As the experimental observations at $30 \mathrm{eV}$ and $70 \mathrm{eV}$ are similar, only $30 \mathrm{eV}$ results are shown 
here. At $200{ }^{\circ} \mathrm{C}$, no real damage or morphological modification occurred on the samples (Fig. 1a). Both energy levels showed similar nanostructures on the surface at $600{ }^{\circ} \mathrm{C}$, however $30 \mathrm{eV}$ sample formed rod-shape nanostructures with smaller area fraction (Fig. 1b). At $900{ }^{\circ} \mathrm{C}$, large tungsten asperities (stone-shape structures) are observed on both surfaces, while at $30 \mathrm{eV}$ surface was also nanopatterned with pinholes (Fig. 1c). It should be noted that the energy of the He ions should be at least $\sim 480 \mathrm{eV}$ in order to induce displacement damage in tungsten [21]. Therefore, even at $70 \mathrm{eV}$, no direct knock-on displacement from collision cascade is possible. Defects at these energies can only occur due to trap mutation or loop punching. Both of these mechanisms require bubble formation and growth. In the trap mutation mechanism, interstitials are emitted when He bubbles grow [22]. Whereas in loop punching, dislocation loops are punched out from highly pressurized bubbles [21].

The rod-shaped structures documented in Fig. 1b, was also observed by other researchers at a similar energy $(50 \mathrm{eV})$, but at a higher fluence and flux $\left(6 \times 10^{24} \mathrm{~m}^{-2}\right.$ and $\left.1.6 \times 10^{22} \mathrm{~m}^{-2} \cdot \mathrm{s}^{-1}\right)$ and temperature of $1127^{\circ} \mathrm{C}$ [16]. Those rod-shape structures are conjectured to form due to the swelling caused by bubble coalescence, which can distort the surface. The rods eventually evolve into the early-stages of fuzz formation [16]. In our case, rod-shaped structures were observed only at $600{ }^{\circ} \mathrm{C}$ and suppressed at higher temperatures $\left(900^{\circ} \mathrm{C}\right)$, where bubble coalescence effect should be larger. Moreover, bubble coalescence is very limited due to low bubble diffusion at $600{ }^{\circ} \mathrm{C}$ [9]. Cross-section TEM images of the modified surface can explain the underlying mechanisms (Figure 2). The rod-shaped structures are actually extending from the grains. As a result of this material transport, grains get thinner around the nanostructures (Fig. 2a). Figure 2b shows a high resolution image of a rod-shape structure and the grain from where it is extended. The distance between lattice planes is measure to be $\sim 0.32 \mathrm{~nm}$ indicating a $\{100\}$ type 
orientation. Under-focus, bright field conditions (Figures 2c\&d) show high density of bubbleshape bright contour structures $(\sim 10 \mathrm{~nm})$ inside the grains but not in the rods, suggesting a contribution from high density of defects on the surface, originating from either trap mutation or loop punching.

Therefore, we speculate a combination of two mechanisms to cause capillary-type forces and upward diffusion of tungsten atoms for rod-shape structure formation: 1) stresses caused by bubbles (lateral stresses) [23] 2) He accumulation (residual stresses) [24] and the strain fields from the defects. Similarly, El-Azab and Liang [25] observed nanostructures (ring-shape) on metal films exposed to oxygen plasma. Their theoretical analysis suggested stress-driven surface diffusion to play a role in the nanostructure formation. According to their study, surface diffusion starts from localized surface defects that may be produced by vacancy condensation. In another study, enhanced surface diffusion is expected to occur due to particle-momentum transfer and large defect concentration, which increases the diffusion rate [26]. Moreover, several studies used lateral stress models to describe blister formation due to He trapping [27, 28] (for more information regarding existing stress models we refer to the review paper by Donnelly [29]). At higher temperatures $\left(\mathrm{T}>1200{ }^{\circ} \mathrm{C}\right)$, however, lateral diffusion can dominate and suppresses the formation of the rod shape structures. In order to restart the upward diffusion and offset the lateral diffusion at high temperatures $\left(\mathrm{T}>1200^{\circ} \mathrm{C}\right)$, larger bubbles and higher lateral stresses are needed. These are only possible at higher fluence and fluxes [16].

In addition to cross-section TEM results, electropolished TEM samples are also irradiated in order to elaborate the role of bubbles in the surface modification of $\mathrm{W}$ at early stages. Fluence varied under the low energy of $30 \mathrm{eV}$ and the temperature of $900{ }^{\circ} \mathrm{C}$. In conjunction, TEM samples are also imaged with SEM from both sides (irradiated side and non- 
irradiated side). At $1 \times 10^{20} \mathrm{~m}^{-2}$, TEM microstructures showed no bubbles (Fig. 3a). At $1 \times 10^{21} \mathrm{~m}^{-2}$, however, bubbles of 3-4 $\mathrm{nm}$ are observed (Fig. 3b). Figure $3 \mathrm{c}$ shows the morphology at $1 \times 10^{20}$ $\mathrm{m}^{-2}$ where no bubbles were observed. Morphology becomes severe at $1 \times 10^{21} \mathrm{~m}^{-2}$ (Fig. $3 \mathrm{~d}$ ), the fluence that results in only 3-4 nm bubbles with no coalescence (Fig. 3b). The uniform density of bubbles in the grains, however, does not match the size of the nanopatterns on the surface (Figs. $3 c \& d)$ and thus cannot explain the surface damage observed. This suggests that the surface modification can start regardless of bubble coalescence. SEM results from non-irradiated sides confirmed no visible surface damage, in agreement with our previous studies showing that temperature alone is not enough to cause any significant damage on TEM samples.

Recently, Miyamoto et al. performed in-situ TEM/helium irradiation on tungsten [30]. At temperatures over $1000{ }^{\circ} \mathrm{C}$, the thin tungsten surfaces start to experience morphology changes even without helium irradiation. Moreover, annealing of pre-irradiated samples (samples with helium bubbles) results in morphology similar to fuzz formation. Enhanced surface diffusion (due to bubble formation) driven by surface tension are speculated to cause these observations. Stresses induced by bubbles and defects (due to loop punching and trap-mutation) can affect surface diffusion and surface tension.

Parallel to recent literature and our $600{ }^{\circ} \mathrm{C}$ results, surface stresses due to the formation of large defect concentrations may be responsible from the surface damage at $900{ }^{\circ} \mathrm{C}$. This large defect concentration can be induced by large He concentration on the near surface. Enhanced mobility of the defects enabled by vacancy migration in tungsten at higher temperatures and the irradiation-enhanced diffusion can exacerbate the surface modifications. Bubble coalescence alone is not sufficient for damage initiation. 
Increasing fluence at $900{ }^{\circ} \mathrm{C}$ produced large stone-shape asperities on the surface, which to our knowledge has been observed for the first time on tungsten surfaces in this work. Figure 4 shows the morphological changes on the surface vs fluence during He irradiation at $30 \mathrm{eV}$. The stone-shaped asperities and the pinholes at $1 \times 10^{23} \mathrm{~m}^{-2}$ (Fig. 1c and Fig. 4e) are also studied by cross-section TEM. Low-resolution images (Figs. 5a\&b) suggest that the stone-shaped structures are reminiscent of eroded grains. X-ray photoelectron spectroscopy (XPS) analysis (not shown here) on the bulk samples showed only tungsten and confirmed no impurities on the sample. Larger bubbles are expected to occur at this fluence when vacancy migration is enabled. Thus, we speculate that erosion of the grains occurred due to bubble bursting or bubble-induced stress. Eroded grain in this case has $\{110\}$ type orientation $(\sim 0.22 \mathrm{~nm}$ distance between the planes corresponding to type plane - Fig. 5c). On the other hand, some grains are nanopatterned due to pinhole formation (Fig. 5d). In addition, some grains show fiber-like structures, which resemble the fuzz structure observed at higher flux and fluence irradiation [10]. Eroded grains in the same picture (Fig. 5e) suggest these structures can also be result of grain erosion and bursting, which are suggested to begin with bubble coalescence and their bisection on the surface [16]. Moreover, the erosion of the grains in ultrafine tungsten can be exacerbated due to large bubbles forming on the grain boundaries. In a recent study, we showed larger bubbles on the grain boundaries compared to the grain interiors of ultrafine and nanocrystalline tungsten during insitu irradiation of TEM samples with $2 \mathrm{keV} \mathrm{He} \mathrm{[31].} \mathrm{Although} \mathrm{ultrafine-grained} \mathrm{tungsten} \mathrm{has} \mathrm{a}$ higher threshold to fuzz formation under high flux $\left(6 \times 10^{23}\right.$ ions $\left.\mathrm{m}^{-2} \mathrm{~s}^{-1}\right)$ radiation [32], such bursting and erosion at low fluxes should be considered in the future when using tungsten-based materials in the divertor regions of fusion reactors. The bursting and erosion of these grains from 
ultrafine-grained tungsten and its effect on the plasma performance will require further analysis and in-situ experiments in tokamak environments.

\section{Summary}

We studied the response of ultrafine tungsten surfaces exposed to low flux $\left(\sim 10^{20}\right.$ ions $\mathrm{m}^{-}$ $\left.{ }^{2} \mathrm{~s}^{-1}\right)$, low fluence $\left(10^{21}-10^{23}\right.$ ions $\left.\mathrm{m}^{-2}\right) \mathrm{He}$ irradiation. At $600{ }^{\circ} \mathrm{C}$ and $30 \mathrm{eV}$, rod-shaped nanostructures are observed on the surface. Cross-section TEM analysis within the individual grains and rods, confirmed that bubble formation and coalescence alone is not sufficient for surface damage. A capillary-type upward diffusion mechanism is suggested, which is exacerbated by surface stresses caused by bubbles and accumulation of He atoms. Similarly, TEM studies at higher temperature $\left(900{ }^{\circ} \mathrm{C}\right)$ under the same low flux and fluence, showed surface damage with minimal bubble densities. Size of the bubbles did not match the physical size of the nanostructures. Increasing fluence to $10^{23}$ ions $\mathrm{m}^{-2}$ at $900{ }^{\circ} \mathrm{C}$ resulted in large asperities (a combination of rod- and stone-shape structures). These structures are thought to be the remains of eroded ultrafine grains due to bubble bursting. Eroded grains also led to fiberform structures, similar to the ones observed at high flux, high fluence studies.

\section{Acknowledgements}

The authors acknowledge Daniel Klenosky and Tian Qiu for the help in preparing the samples prior to irradiation. This research is supported by the U.S. Department of Energy's 2010 Early Career Award DE-SC0004032. The FOM authors are supported by the Stichting voor Fundamenteel Onderzoek der Materie (FOM), which is financially supported by the Nederlandse Organisatie voor Wetenschappelijk Onderzoek (NWO). The work is supported by the European 
Communities under the contract of Association between EURATOM and FOM and carried out within the framework of the European Fusion Program, and of the European Taskforce on Plasma-Wall Interactions. K. Hattar acknowledges the Division of Materials Science and Engineering, Office of Basic Energy Sciences, U.S. Department of Energy. Sandia National Laboratories is a multi-program laboratory managed and operated by Sandia Corporation, a wholly owned subsidiary of Lockheed Martin Corporation, for the U.S. Department of Energy's National Nuclear Security Administration under contract DE-AC04-94AL85000. The authors would like to thank Professor Anter El-Azab for the helpful discussions.

\section{Figure Captions}

Figure 1: SEM micrographs of ultrafine-grained tungsten samples irradiated with $30 \mathrm{eV} \mathrm{He}$ particles to a fluence of $1 \times 10^{23} \mathrm{~m}^{-2}$ at (a) $200{ }^{\circ} \mathrm{C}$, (b) $600{ }^{\circ} \mathrm{C}$ and (c) $900{ }^{\circ} \mathrm{C}$

Figure 2: TEM micrographs of the ultrafine-grained tungsten sample irradiated with $30 \mathrm{eV} \mathrm{He}$ particles to a fluence of $1 \times 10^{23} \mathrm{~m}^{-2}$ at $600{ }^{\circ} \mathrm{C}$ showing (a) several rod-shape nanostructures; (b) high resolution image of a rod-shape nanostructure; (c) region of bubbles in between two rodshape nanostructures and (d) region of highly dense large bubbles $\sim 10 \mathrm{~nm}$ below the sample surface. Images in (c) and (d) were taken at under-focus conditions.

Figure 3: TEM micrographs of TEM samples irradiated with $30 \mathrm{eV}$ He particles at $900{ }^{\circ} \mathrm{C}$ to a fluence of (a) $1 \times 10^{20} \mathrm{~m}^{-2}$ (no bubbles were observed) and (b) $1 \times 10^{21} \mathrm{~m}^{-2}$ (uniform distribution 
of 3-4 nm He bubbles). Images were taken at under-focus conditions. SEM micrographs of TEM samples at the same fluences (c) and (d), respectively, show increasing amount of surface damage with fluence.

Figure 4: SEM micrographs of ultrafine-grained tungsten samples irradiated with $30 \mathrm{eV} \mathrm{He}$ particles at $900{ }^{\circ} \mathrm{C}$ to different fluences: (a) $5 \times 10^{20} \mathrm{~m}^{-2}$, (b) $1 \times 10^{21} \mathrm{~m}^{-2}$, (c) $5 \times 10^{21} \mathrm{~m}^{-2}$, (d) $1 \mathrm{x}$ $10^{22} \mathrm{~m}^{-2}$, and (e) $1 \times 10^{23} \mathrm{~m}^{-2}$

Figure 5: TEM micrographs of the ultrafine-grained tungsten sample irradiated with $30 \mathrm{eV} \mathrm{He}$ particles to a fluence of $1 \times 10^{23} \mathrm{~m}^{-2}$ at $900{ }^{\circ} \mathrm{C}$ showing (a) and (b) eroded grain leaving stoneshape nanostructures; (c) high resolution of one stone-shape nanostructure; (d) region of a nanostructures grain (pinholes) and (e) eroded grain leaving fiber-form nanostructures

\section{References}

[1] J.W. Davis, V.R. Barabash, A. Makhankov, L. Plöchl, K.T. Slattery, J. Nucl. Mater., 258 (1998) 308312.

[2] R. Neu, R. Dux, A. Kallenbach, T. Pütterich, M. Balden, J. Fuchs, A. Herrmann, C. Maggi, M. O'Mullane, R. Pugno, Nucl. Fusion, 45 (2005) 209-218.

[3] R.P. Doerner, M.J. Baldwin, P.C. Stangeby, Nucl. Fusion, 51 (2011) 043001.

[4] S. Takamura, T. Miyamoto, N. Ohno, Nucl. Fusion, 52 (2012) 123001.

[5] D. Nishijima, M.Y. Ye, N. Ohno, S. Takamura, J. Nucl. Mater., 329 (2004) 1029-1033.

[6] B.B. Cipiti, G.L. Kulcinski, J. Nucl. Mater., 347 (2005) 298-306.

[7] M.J. Baldwin, R.P. Doerner, J. Nucl. Mater., 404 (2010) 165-173. 
[8] S.B. Gilliam, S.M. Gidcumb, N.R. Parikh, D.G. Forsythe, B.K. Patnaik, J.D. Hunn, L.L. Snead, G.P. Lamaze, J. Nucl. Mater., 347 (2005) 289-297.

[9] S. Sharafat, A. Takahashi, Q. Hu, N.M. Ghoniem, J. Nucl. Mater., 386 (2009) 900-903.

[10] S. Kajita, N. Yoshida, R. Yoshihara, N. Ohno, M. Yamagiwa, J. Nucl. Mater., 418 (2011) 152-158.

[11] X.-M. Bai, A.F. Voter, R.G. Hoagland, M. Nastasi, B.P. Uberuaga, Science, 327 (2010) 1631-1634.

[12] N. Nita, R. Schaeublin, M. Victoria, J. Nucl. Mater., 329 (2004) 953-957.

[13] K. Hattar, M.J. Demkowicz, A. Misra, I.M. Robertson, R.G. Hoagland, Scripta Mater., 58 (2008) 541-544.

[14] B.N. Singh, T. Leffers, W.V. Green, M. Victoria, J. Nucl. Mater., 125 (1984) 287-297.

[15] H. Ullmaier, Nucl. Fusion, 24 (1984) 1039.

[16] S. Kajita, W. Sakaguchi, N. Ohno, N. Yoshida, T. Saeki, Nucl. Fusion, 49 (2009) 095005.

[17] O. El-Atwani, M. Efe, B. Heim, J.P. Allain, J. Nucl. Mater., 434 (2013) 170-177.

[18] M. Efe, O. El-Atwani, Y. Guo, D.R. Klenosky, Scripta Mater., 70 (2014) 31-34.

[19] J. Westerhout, W.R. Koppers, W.A.J. Vijvers, R.S. Al, S. Brezinsek, S. Brons, H.J.N. van Eck, R. Engeln, B. de Groot, R. Koch, Phys. Scr., T128 (2007) 18.

[20] K. Bystrov, T.W. Morgan, I. Tanyeli, G. De Temmerman, M.C.M. van de Sanden, J. Appl. Phys., 114 (2013) 133301.

[21] Y. Minyou, Plasma Sci. Technol, 7 (2005) 2828.

[22] L.M. Caspers, R.H.J. Fastenau, A. Van Veen, W.F.W.M. Van Heugten, Phys. Status Solidi A, 46 (1978) 541-546.

[23] R. Behrisch, J. Bo/ttiger, W. Eckstein, U. Littmark, J. Roth, B.M.U. Scherzer, Appl. Phys. Lett., 27 (1975) 199-201.

[24] T. Som, S. Bhargava, M. Malhotra, H.D. Bist, V.N. Kulkarni, S. Kumar, Appl. Phys. Lett., 72 (1998) 3014-3016.

[25] A. El-Azab, Y. Liang, Philos. Mag., 83 (2003) 3847-3869.

[26] S.M. Myers, Nucl. Instrum. Methods, 168 (1980) 265-274.

[27] J. Roth, R. Behrisch, B.M.U. Scherzer, J. Nucl. Mater., 53 (1974) 147-153.

[28] E.P. EerNisse, S.T. Picraux, J. Appl. Phys., 48 (1977) 9-17.

[29] S.E. Donnelly, Radiat. Eff., 90 (1985) 1-47. 
[30] M. Miyamoto, T. Watanabe, H. Nagashima, D. Nishijima, R.P. Doerner, S.I. Krasheninnikov, A. Sagara, N. Yoshida, Phys. Scr., T159 (2014) 014028.

[31] O. El-Atwani, J.A. Hinks, G. Greaves, S. Gonderman, T. Qiu, M. Efe, J.P. Allain, Sci. Rep., 4 (2014) 4716.

[32] O. El-Atwani, S. Gonderman, M. Efe, G.D. Temmerman, T. Morgan, K. Bystrov, D. Klenosky, T. Qiu, J.P. Allain, Nucl. Fusion, 54 (2014) 083013. 


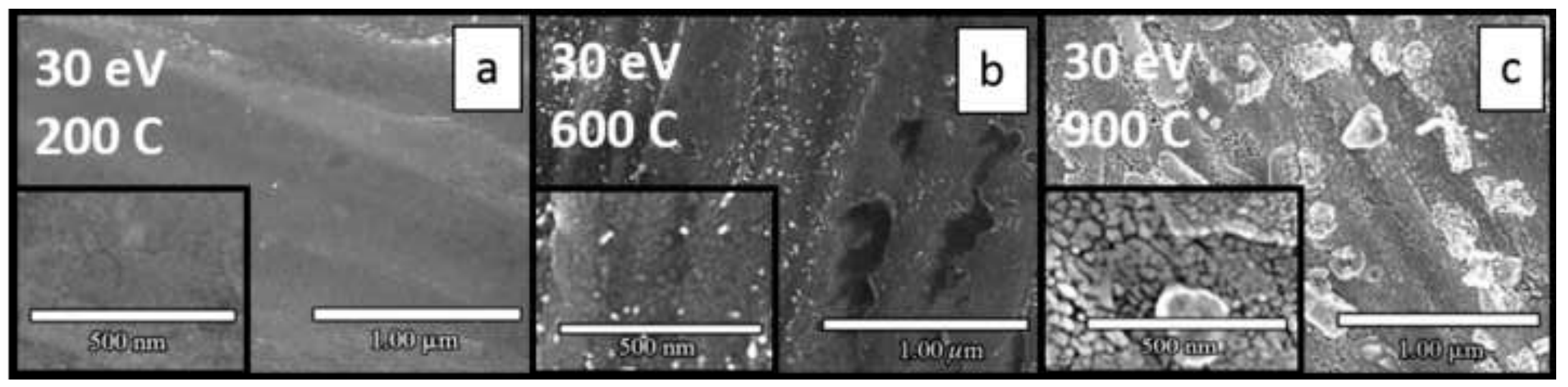



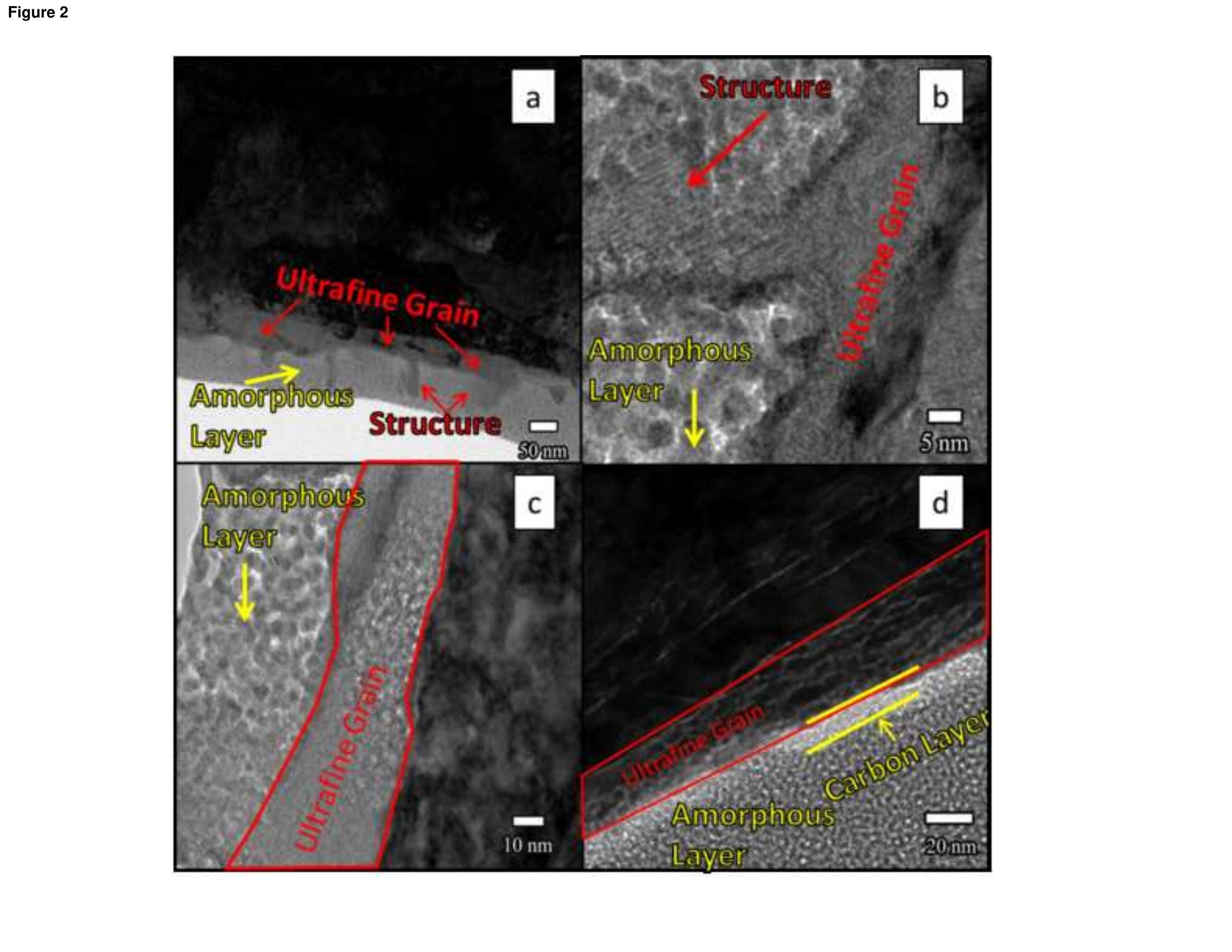

.

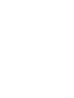
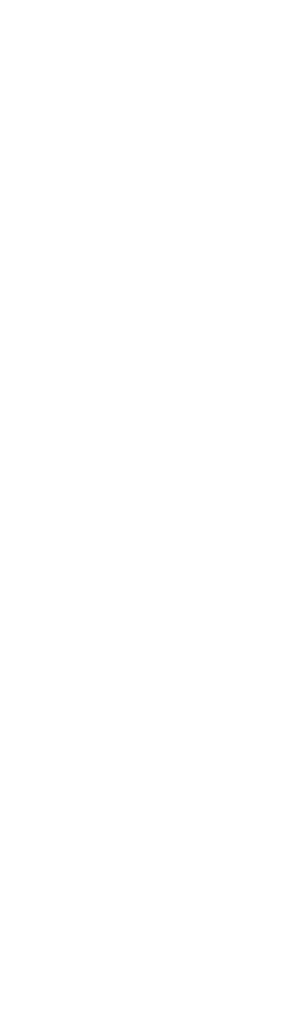


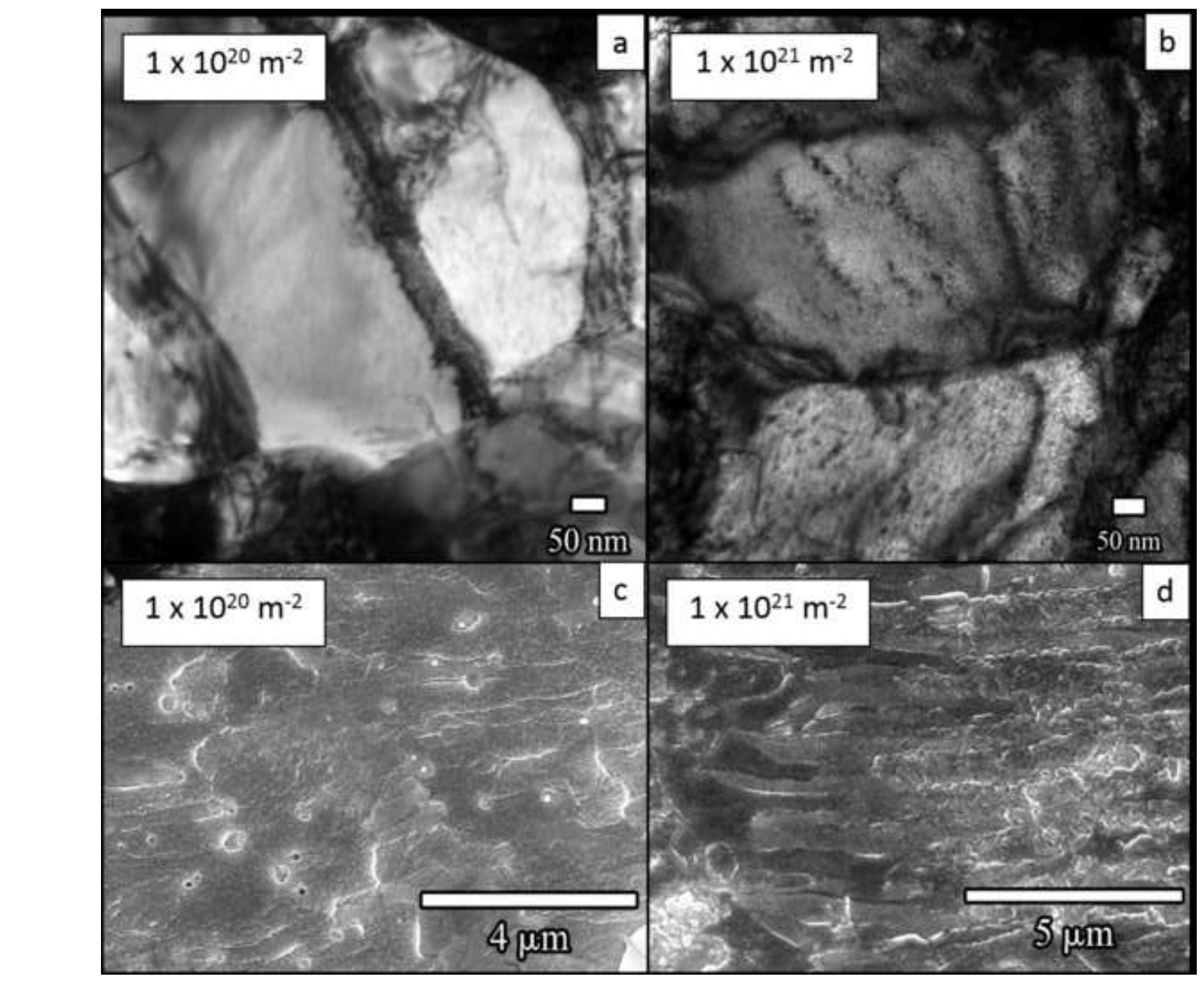

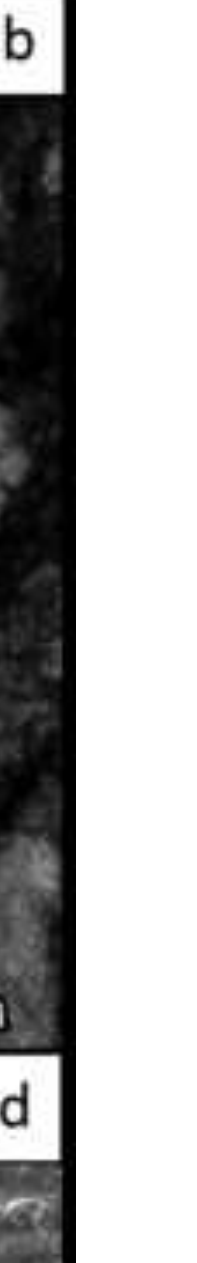




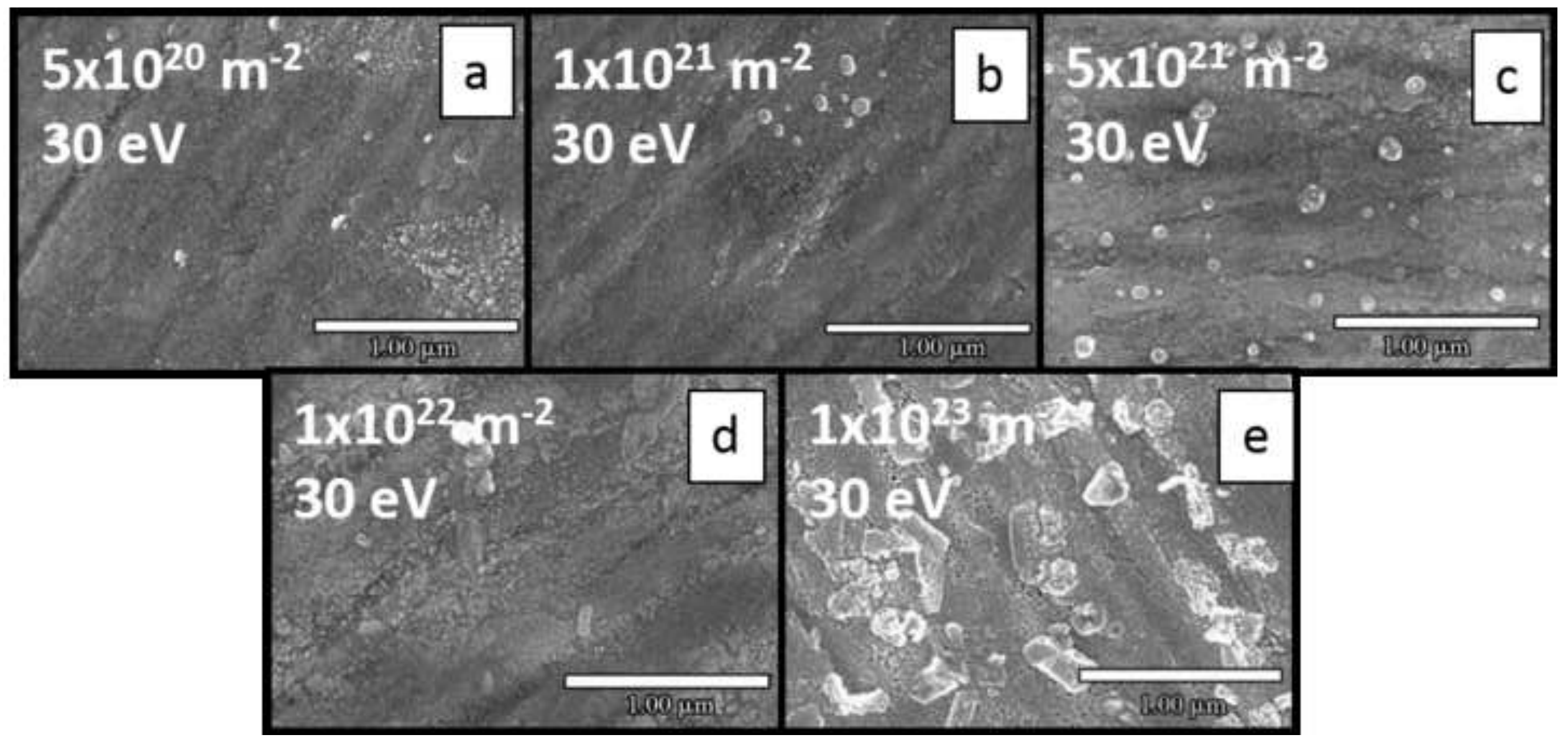


